\title{
Pilomatricoma Maligno em ovino nativo do Estado de Mato Grosso do Sul
}

\author{
Malignant Pilomatricoma in native sheep in Mato Grosso do Sul State, Brazil \\ Dietrich Pizzigatti ${ }^{1}$, Charles Ferreira Martins ${ }^{2}$, Fernando Arévalo Batista ${ }^{2} \&$ Olímpio Crisóstomo \\ Ribeiro ${ }^{3}$
}

\begin{abstract}
RESUMO
Até o presente momento, são raras as publicações que tratam da ocorrência de pilomatricoma em animais. O pilomatricoma é um tumor que pode ser de origem benigna ou maligna, sendo descrito inicialmente como "epitelioma necrosante e calcificante de Malherbe". É um tumor de evolução lenta e progressiva, de formato variável, com origem a partir da matriz pilosa. Este relato descreve o caso de uma ovelha de origem nativa, com lesão de aspecto tumoral, de localização na narina direita com consistência firme, coloração vermelho-azulada e $2,5 \mathrm{~cm}$ de diâmetro. O exame histopatológico identificou a presença de células tumorais de origem epitelial, com áreas de degeneração. Discreto pleomorfismo, em contraste com alto índice mitótico, dominava o padrão morfológico da lesão. O estroma foi constituído por tecido conectivo, infiltrado por um pequeno número de células inflamatórias. O padrão histopatológico observado no presente caso permitiu caracterizar a massa como pilomatricoma maligno.
\end{abstract}

Descritores: pilomatricoma, ovino, histopatologia.

\section{ABSTRACT}

At to the present moment, publications dealing with pilomatricoma in animals has been a rare occurrence. Pilomatricoma is a tumor that may be of benign or malignant origin, that has initially been described as "necrotizing and calcifying epithelioma of Malherbe". It is a tumor of slow and progressive evolution, of variable shape, from the hair shaft matrix. The present report describes a case in a native ewe, that presented lesions of tumoral aspect, localized in the right nare, with firm consistence, red-blue in color and $2,5 \mathrm{~cm}$ in diameter. At histopathologic examination it was identified the presence of tumoral cells of epithelial origin, with areas of degeneration. A discrete pleomorfism, in contrast to a high mitotic index dominated the lesion morphologic pattern. The stroma was made out of connective tissue that was infiltrated by a small number of inflammatory cells. Histopathologic pattern observed in this case allowed it to be characterized as the mass as a malignant pilomatricoma.

Key words: pilomatricoma, ewe, histopathology. 


\section{INTRODUÇÃO}

O pilomatricoma é um tumor que pode ser de origem benigna ou maligna, sendo descrito inicialmente como "epitelioma necrosante e calcificante de Malherbe" [5]. Em 1961, pesquisadores [4] concluíram que este tumor tinha origem a partir da matriz pilosa, e não das glândulas sebáceas [7]. Posteriormente, confirmado através de técnicas de microscopia óptica, eletrônica e histoquímica [9,6]. Considerado ainda como um hamartoma, com diferenciação para células da matriz do córtex e da bainha interna do pêlo $[10,11]$, sua etiologia permanece desconhecida.

Mais comumente citado na medicina humana, as dimensões do tumor estão entre $33 \mathrm{~mm}$ até $13,5 \mathrm{~cm}$ de diâmetro, sendo a grande maioria deles de caráter solitário. Apenas 2 a 3,5\% aparecem como lesões múltiplas e apresentam aspecto nodular dérmico ou subdérmico, móvel e de consistência pétria e são encontrados, mais freqüientemente, na região da cabeça, pescoço e extremidades superiores, apesar de já terem sido encontrados em diversas outras regiões do corpo [1,15]. Em Medicina Veterinária, o pilomatri-coma é mais comumente diagnosticado em cães, e é raro em gatos ou em outros animais domésticos, sendo mais encontrado no dorso, pescoço, tórax e cauda [5,11].

$\mathrm{O}$ caso apresentado é sobre o primeiro diagnóstico de pilomatricoma no estado de Mato Grosso do Sul, e objetiva descrever os sinais clínicos e aspectos morfológicos deste tumor em um animal da espécie ovina.

\section{RELATO DO CASO}

Uma fêmea da espécie ovina sem raça definida, de quatro anos de idade, foi atendida no Hospital Veterinário da Universidade para o Desenvolvimento do Estado e da Região do Pantanal (UNIDERP) para avaliação clínica. A ovelha apresentava estado de debilitação orgânica, com sinais de fotossensibilização hepatógena. Durante a inspeção, se observou uma lesão de aspecto tumoral, localizada na narina direita. A massa era móvel e bem circunscrita, tinha consistência firme, coloração vermelho-azulada e $2,5 \mathrm{~cm}$ de diâmetro. A informação do tratador foi de que o aparecimento da lesão fora notado há oito meses.

Diante da provável natureza tumoral, procedeu-se a avaliação histopatológica. Ao exame de microscopia ótica, verificou-se tratar de uma lesão neoplásica, com envolvimento da derme e do tecido subcutâneo. As células tumorais de origem epitelial foram caracterizadas como formadoras de epitélio estratificado pavimentoso queratinizado, com áreas de degeneração (Figuras 1 e 4). O derma exibia células basilóides (Figura 2) com núcleo pequeno, hipercromático e escasso citoplasma, que se arranjavam como ilhas de células neoplásicas, onde depósitos de queratina e células fantasmas, em degeneração, foram observadas (Figura 3). Um discreto pleomorfismo, em contraste com alto índice mitótico, dominava o padrão morfológico da lesão. $\mathrm{O}$ estroma foi constituído por tecido conectivo, infiltrado por um pequeno número de células inflamatórias.

Após o procedimento cirúrgico de excisão da massa, o animal não apresentou sinais de recidiva da lesão.

\section{DISCUSSÃO}

No presente relato, foi observado que a massa tumoral apresentou evolução lenta e progressiva, sendo móvel e circunscrita, de consistência firme. Havendo, entretanto, casos de crescimento rápido [10]. Por vezes, poderá se manifestar sob aspectos inusitados, tendo sido descritas formas angiomatosas, xantomatosas, verrucosas, ulceradas, perfurantes e pseudo-bolhosas.

As diferenças entre os pilomatricomas benignos e os malignos estão basicamente na citologia e no comportamento de desenvolvimento, sendo de caráter nodular solitário ou invasivo e o infiltrado linfático presente no estroma do benigno, encontra-se na periferia do tumor do maligno [5].

Embora considerado um tumor raro, alguns autores acreditam que ele seja relativamente freqüente, todavia, mal diagnosticado na Medicina Veterinária [5]. O diagnóstico clínico é difícil e é considerado impossível [10]. A biópsia excisional, metodologia utilizada neste estudo, ou por punção por agulha fina são métodos diagnósticos fundamentais para neoplasias cutâneas $[2,8,14]$. Dificuldades em transfixar o tumor podem ser encontradas, em razão da concentração óssea no interior da massa de alguns casos $[1,5,15]$.

Clinicamente, o diagnóstico diferencial deve ser feito com cistos benignos (epidérmico ou triquilemial), hemangioma, ceratoacantoma, dermatofibroma, carcinoma basocelular, carcinoma espinocelular, goma bacteriana ulcerada, angiossarcoma, melanoma, calcificações cutâneas e, mesmo, câncer de mama. Contudo, sua diferenciação histológica é o único método, apesar de sua reduzida precisão [1]. 


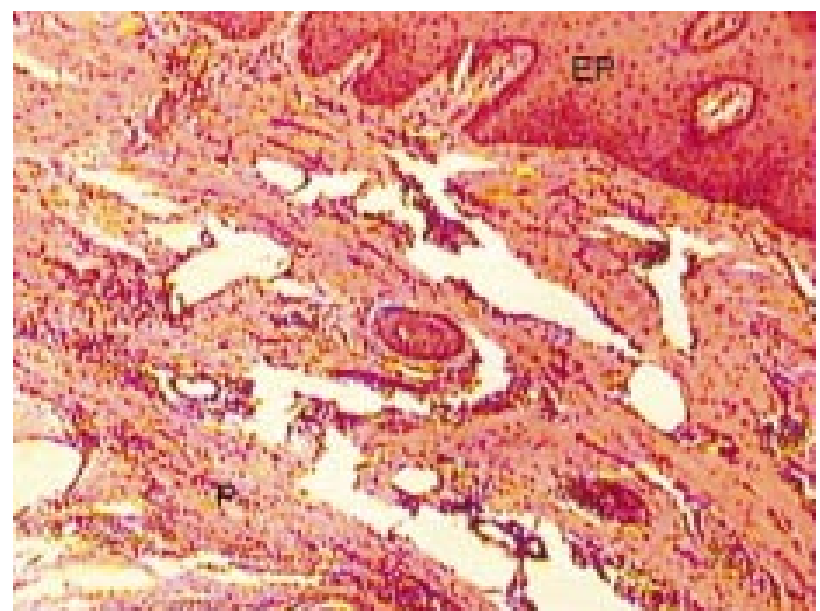

Figura 1. Fotomicrografia: Aspecto histológico da neoplasia, cujas células tumorais se arranjam como epitélio estratificado pavimentoso (EP) com infiltrações do estroma. Observe o pleomorfismo (P) (H \& E 50x).

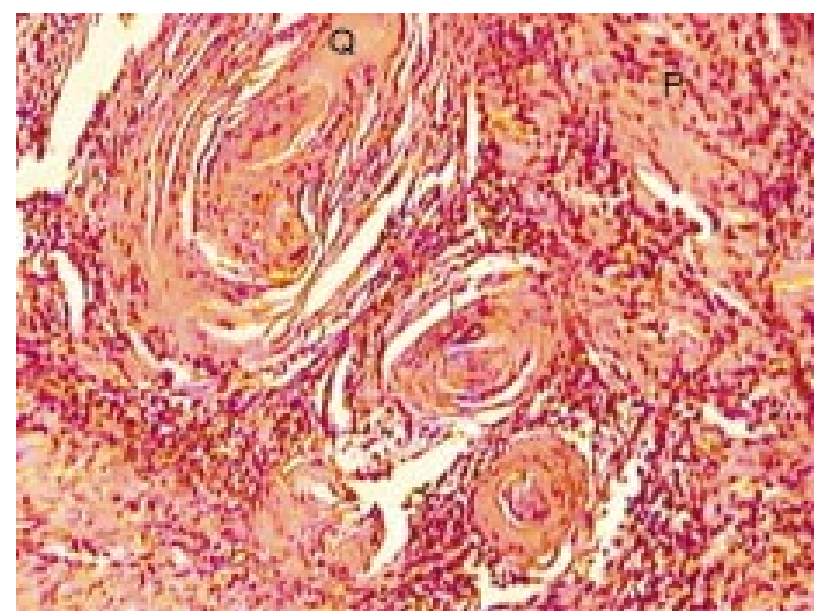

Figura 3. Fotomicrografia: Aspecto histológico da neoplasia, do intenso pleomorfismo (P) e da deposição de queratina (Q) (H \& E 100x).

Em uma biopsia de punção em massa profunda, assintomática, maciça, eritematosa, que media de $4-4,4 \mathrm{~cm}$ no pé esquerdo de uma mulher de 35 anos de idade [2], células sombreadas, escamóides e agregações basilóides mais proeminentes na massa, além de áreas de calcificação e células gigantes adventícias e células nervosas, serviram para caracterizar um pilomatricoma. No presente estudo, células basilóides foram observadas no derma, o que está de acordo com o achado dos autores supracitados, além do pleomorfismo e da presença de células atípicas e do alto índice mitótico.

Também foi constatado, histologicamente, que a massa tumoral era arredondada, de contornos bem delimitados, circunscrita por cápsula conjuntiva e de

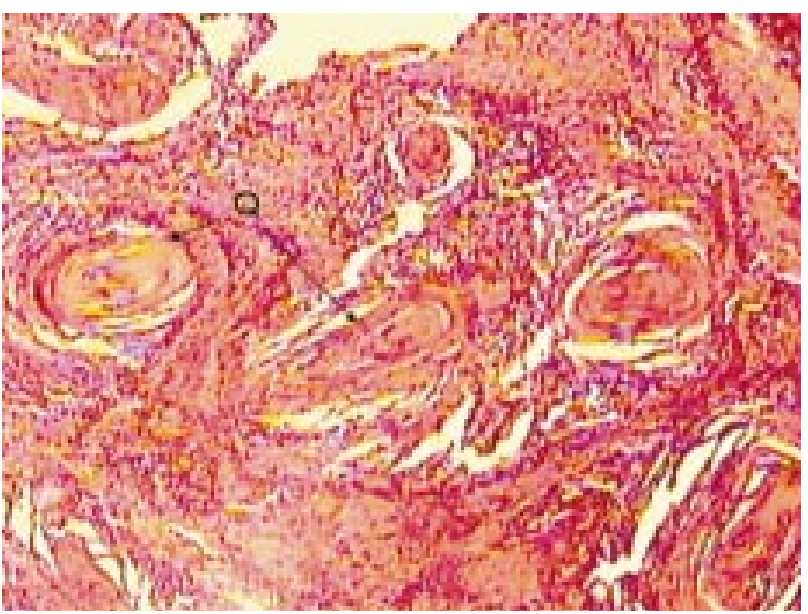

Figura 2. Fotomicrografia: Aspecto histológico de neoplasia epitelial com intenso pleomorfismo $(\mathrm{P})$ e deposição de queratina $(\mathrm{Q})(\mathrm{H} \& \mathrm{E} 50 \mathrm{x})$.

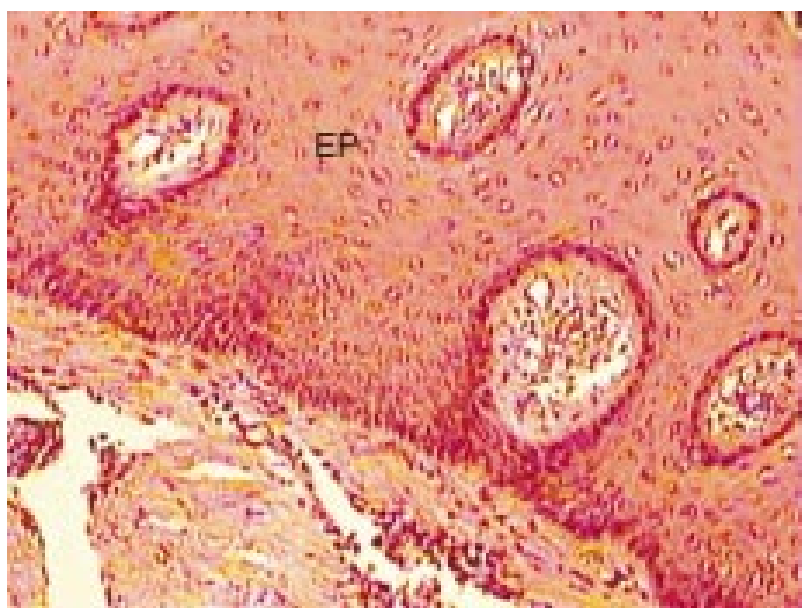

Figura 4. Fotomicrografia: Aspecto histológico da neoplasia cujo epitélio origem é o estratificado pavimentoso (EP) (H \& E x10).

localização profunda na derme [10,11]. Células basofílicas e células-sombra no estroma celular são achados comuns. Em alguns tumores, a presença de células basofílicas pode ser um achado raro, porém é mencionado por diferentes autores [11,12], o que, no presente relato, foi observado. É possível observar a transição de células basofílicas às células-sombra. As células baso-fílicas imaturas diferenciam-se depois de uma parada temporária no ciclo celular das células escamosas ou células de transição [3]. O caminho escamoso representa completa diferenciação epitelial, já o de transição, é relacionado com diferenciação da deterioração trico-citária que promove apoptose e formação de células-sombra inoperantes. Áreas de queratinização, calcificação e de ossificação podem ser vistas no 
estroma, além de infiltrado de células inflamatórias crônicas e células gigantes, com presença de figuras mitóticas [15]. Células hipercromáticas proliferativas ativas, com numerosas mitoses e infiltração de estruturas circunvizinhas, são características microscópicas sugestivas de piloma-tricoma maligno $[1,12]$.

O tratamento do pilomatricoma deste caso incluiu excisão cirúrgica. Além deste procedimento, alternativamente se pode empregar crioterapia e controle químico [11]. Sucesso foi obtido no controle de pilomatricomas múltiplos, benignos, com $1 \mathrm{mg} / \mathrm{kg}^{(-1)}$ de isotretinoina, diariamente [13]. Para outros autores, o procedimento incisivo cirúrgico é recomendado, sendo a recidiva incomum, desde que a excisão tenha sido eficaz $[1,12]$. Contudo, excisões incompletas podem levar a recidivas $[1,12]$, fato que não foi observado neste estudo. Formas recidivantes, de aspecto agressivo, são descritas na medicina humana, com mais de 40 exemplos de variantes malignas, denominadas pilomatricoma carcinomatoso [15]. O uso cirúrgico de laser de dióxido de carbono ao redor da lesão, foi eficiente após o tamponamento da ferida cirúrgica com mucosa intestinal de suíno [2,14].

Enfim, este animal apresentou padrão histopatológico de pilomatricoma maligno.

\section{REFERÊNCIAS}

1 Azulay R.D. \& Azulay D.R. 2006. Dermatologia. 4.ed. Rio de Janeiro: Guanabara Koogan, 513p.

2 Ciralik H., Coban Y.K. \& Arican O. 2006. A case of perforating pilomatricoma. Journal of Dermatology. 33: 394-398.

3 Fayyazi A., Soruri A., Radzun H.J., Peters J.H. \& Berger H. 1997. Cell renewal, cell differentiation and programmed cell death (apoptosis) in pilomatrixoma. British Journal of Dermatology. 37: 714-720.

4 Forbis R. \& Helwig E.B. 1961. Pilomatrixoma (calcifying epithelioma). Archive of Dermatolgy. 83: 606-618.

5 Goldshmidt M.H. \& Hendrick M.J. 2002. Tumors of the skin and soft tissues: pilomatricoma. In: Meuten D.J. (Ed). Tumors in domestic animals. 4th edn. Iowa: Blackwell Publishing, pp.61-63.

6 Hashimoto K., Nelson R.G. \& Lever W.F. 1966. Calcifying epithelioma of malherbe. Histochemical and electron microscopic studies. Journal invest of dermatology. 46: 391-408.

7 Malherbe A. \& Chenantais I. 1880. Note sur l'épithélioma calcifié de glandes sebacées. Bulletins de la Société Anatomique de Paris. 5: 169.

8 Maserdotti C. \& Ubbiali F.A. 2002. Fine needle aspiration cytology of pilomatricoma in three dogs. Veterinary Clinical Pathology. 31: 22-25.

9 McGovern M.H. 1965. Ultrastructure of Pilomatrixoma (calcifying epithelioma). Cancer. 18: 1445-1456.

10 Pimentel M.I.F., Segura M.T. \& Ramos e Silva M. 1991. Pilomatricoma. In: Anais Brasileiros de Dermatologia. (Rio de Janeiro, Brasil), pp.15-18.

11 Scott W.D., Muller Jr. W.H. \& Griffin C.E. 1995. Muller \& Kirk's small animal dermatology. 5th edn. Philadelphia: Saunders, pp.1015-1016.

12 Silva T.A., Júnior E.F.M., Consolaro A \& Lara V.S. 2003. Pilomatricoma of the auricular region: case report. Brazilian Dental Journal. 14: 223-226.

13 Toma S. \& Noli C. 2005. Isotretinoin in the treatment of multiple benign pilomatrixomas in a mixed-breed dog. Veterinary Dermatology. 16: 346-50.

14 Türel A., Öztürcan S., Sahin M.T., Güçlü G. \& Türkdogan P. 2005. Pilomatricoma: A late onset case in the neck. Otolaryngology-Head and Neck Surgery. 133: 1-2.

15 Weedon D. \& Strutton G. 2002. Skin Pathology: Tumors of cutaneous appendages. 2nd edn. Philadelphia: Churchill Livingstone, pp.869-870.

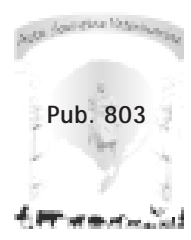

